\title{
INFLUÊNCIA DO POSICIONAMENTO ESTRATÉGICO NA ADOÇÃO DE PRÁTICAS GERENCIAIS FINANCEIRAS NO CONTEXTO DE PEQUENAS INDÚSTRIAS
}

\author{
INFLUENCE OF STRATEGIC POSITIONING ON \\ ADOPTION OF FINANCIAL MANAGEMENT PRACTICES IN THE CONTEXT OF \\ SMALL INDUSTRIES
}

RODNEY WERNKE

Sem vínculo institucional. Endereço: Rua Antônio Philippi, 312 | Centro | 88730$000 \mid$ São Ludgero/SC | Brasil.

Dhttp://orcid.org/0000-0001-5163-5004

rodneywernke1@hotmail.com

\section{IVONE JUNGES}

Universidade do Sul de Santa Catarina. Endereço: Av. José Acácio Moreira, 787| Dehon | 88704-900 | Tubarão/SC | Brasil.

(D)http://orcid.org/0000-0003-1676-5174

ivone.junges@unisul.br

\section{VALENTINA PIRES DE BARROS}

Universidade do Sul de Santa Catarina. Endereço: Av. José Acácio Moreira, 787| Dehon | 88704-900 | Tubarão/SC | Brasil.

(D) http://orcid.org/0000-0003-4848-8466

avalpiress@gmail.com

\section{RESUMO}

O objetivo do estudo foi identificar a influência do posicionamento estratégico na adoção de ferramentas gerenciais financeiras no contexto de pequenas indústrias da microrregião da Amurel e, adicionalmente, buscar resposta para hipótese acerca da possibilidade de que o nível de utilização das práticas de gestão financeira seja igual nas empresas de pequeno porte, independentemente do posicionamento estratégico adotado. Foi utilizada metodologia classificável como descritiva e quantitativa, sendo que a coleta de dados ocorreu por meio de questionário fundamentado na Teoria da Contingência, na análise do posicionamento estratégico e nas ferramentas gerenciais financeiras dos quatro estágios elencados pela International Federation of Accountants. Como resultados, têm-se que as práticas gerenciais do primeiro e do segundo estágio são as mais utilizadas (com média 55,91\% e 69,32\%, respectivamente), se comparadas com os instrumentos integrantes do terceiro (40\%) e do quarto estágio $(44,46 \%)$. A principal contribuição do estudo consiste em apontar evidência estatística de que o posicionamento estratégico escolhido por indústrias de pequeno porte não afeta o nível de utilização das ferramentas financeiras nesse contexto empresarial. 
Palavras-chave: Posicionamento estratégico. Ferramentas gerenciais. Pequenas indústrias.

\begin{abstract}
The objective of the study was to identify the influence of strategic positioning on the adoption of financial management tools in the context of small industries in the AMUREL (Brazilian Portuguese abbreviation for the Laguna Region Municipalities Association) micro-region and, additionally, to seek an answer to the hypothesis about the possibility that the level of use of financial management practices is equal in small companies regardless of strategic positioning adopted. Methodology classified as descriptive and quantitative was used and the data collection has taken place by means of a questionnaire based on the so-called Contingency Theory in the analysis of the strategic positioning and in the financial management tools of the four stages listed by the International Federation of Accountants. As a result, it has been found that the management practices of the first and second stages are the most used (with an average of $55.91 \%$ and $69.32 \%$, respectively) when compared with the instruments belonging to the third (40\%) and fourth stages (44.46\%). The main contribution of the study is to point out statistical evidence that the strategic positioning chosen by small industries does not affect the level of use of financial tools in this business context.
\end{abstract}

Keywords: Strategic positioning. Management tools. Small industries.

\title{
1 INTRODUÇÃ̃O
}

A Teoria da Contingência assenta-se na plataforma teórica que visa identificar como a organização é influenciada por fatores contingenciais, que podem ser quaisquer variáveis que moderem o efeito de uma característica organizacional na performance da empresa (Donaldson, 2001; Chenhall, \& Chapman, 2006; Junqueira, Dutra, Zanquetto Filho, \& Gonzaga, 2016). Nesse rumo, os fatores contingenciais podem ser segregados em dois grupos: externos e internos. No caso dos aspectos externos caberia avaliar a influência da incerteza ambiental (Beuren \& Fiorentin, 2014) e o poder dos clientes (Abdel-Kader \& Luther, 2008; Klein \& Almeida, 2017), enquanto no âmbito dos fatores internos podem ser avaliados itens como a estratégia competitiva adotada (Chenhall, 2006; Rufatto, 2018), a estrutura (Lavarda \& Gorla, 2012; Jordão \& Souza, 2013) e o porte da empresa (Klein \& Almeida, 2017).

Destarte, é cabível considerar que a escolha da prioridade estratégica seja impactada pela análise das forças competitivas existentes no segmento de atuação da companhia, conforme Porter (1991). Com isso, segundo Mintzberg, Ahlstrand e Lampel (2010), a estratégia contribuirá na formatação da estrutura organizacional a ser utilizada, como é o caso do sistema de controle gerencial e das práticas de gestão respectivas (Leite, Diehl, \& Manvailer, 2015). Então, é coerente presumir que as premissas do modelo de forças competitivas influenciam na definição das estratégias genéricas a serem adotadas e que, como as estratégias moldam a estrutura, o sistema de controle gerencial será moldado pela estratégia escolhida (Junqueira et al., 2016).

Como exposto, há diversos fatores que podem modificar a realidade das organizações, o que indica a necessidade de pesquisas que estudem as variáveis que influenciam na utilização de práticas gerenciais financeiras. Entretanto, no contexto das pequenas empresas é mais raro encontrar publicações que foquem esse tema, especialmente pela reduzida base de dados disponíveis a respeito. Essa realidade também é associável às pequenas indústrias da microrregião da Associação dos Municípios da Região de Laguna (Amurel), no sul de Santa Catarina, visto que nenhum estudo acerca do tema foi divulgado com enfoque assemelhado, conforme pesquisa on-line realizada no Portal de 
Periódicos Capes em agosto de 2019.

Nessa direção, a pesquisa ora relatada pretende responder à seguinte questão: qual a influência do posicionamento estratégico na adoção de ferramentas gerenciais financeiras no contexto de pequenas indústrias da microrregião da Amurel? Para essa finalidade foi estabelecido o objetivo de identificar a influência do posicionamento estratégico na adoção de ferramentas gerenciais financeiras no âmbito de pequenas indústrias da microrregião da Amurel.

$\mathrm{O}$ roteiro escolhido para efetuar tal análise consiste em diagnosticar o posicionamento estratégico, conforme preconizado por Porter (1991), para associá-lo às práticas gerenciais financeiras adotadas por empresas fabris de pequeno porte da região da Amurel. Desse modo, utiliza-se um modelo testado em outro contexto empresarial (Junqueira et al., 2016), o que possibilitará comparar os resultados e, concomitantemente, diagnosticar a realidade das pequenas indústrias da Amurel.

A abordagem escolhida pode ser justificada inicialmente pela relevância econômica das pequenas empresas, que são responsáveis por grande parte da geração de emprego e renda no Brasil (Santos, Dorow, \& Beuren, 2016; Almeida, Valadares, \& Sediyama, 2017) e também em países europeus (Malik \& Jasinska-Biliczak, 2018; Nigri \& Baldo, 2018). Além disso, há poucas pesquisas acerca da influência do posicionamento estratégico no âmbito de pequenas empresas industriais, o que permite considerar a existência de uma lacuna de investigação a se explorar, como visado neste estudo.

\section{REVISÃO DA LITERATURA}

Entre as teorias que têm sido utilizadas em investigações acerca do uso de conceitos e ferramentas contábeis está a Teoria da Contingência (Donaldson, 2012; Klein \& Almeida, 2017; Moterle, Wernke, \& Junges, 2019). Essa corrente defende que não existe uma estrutura única (ou melhor) em termos de ser aplicável a todo tipo de organização, visto que cada estrutura organizacional tende a ser formatada a partir de vários fatores do contexto de cada organização (Otley, 2016). Esse posicionamento é compartilhado por Scapens (2006) quando salienta a necessidade do reconhecimento de fatores idiossincráticos exclusivos de determinada empresa para que se possa compreender acerca do uso das práticas de contabilidade gerencial. Adicionalmente, Otley (2016) aduz que toda pesquisa em contabilidade gerencial é essencialmente contingente, uma vez que procura descobrir quando determinadas técnicas podem ser as mais apropriadas para organizações específicas em função das peculiaridades que lhes caracterizam.

Esse contexto pode ser associado também às pequenas empresas fabris (como as abrangidas nesta pesquisa), pois estas enfrentam dificuldades para crescer em mercados de concorrência acirrada, que podem ser atribuídas a fatores contingenciais como estratégia adotada, capacitação de dirigentes e funcionários, poder de barganha perante fornecedores e clientes etc. (Leite, Diehl, \& Manvailer, 2015; Castro, 2015; Siska, 2016; Maletic et al., 2017; Callado, 2016; Klein \& Almeida, 2017; Almeida \& Callado, 2018; Honorio \& Bonemberger, 2019; Oro \& Lavarda, 2019).

Entretanto, nesta pesquisa foi priorizada a identificação da influência do posicionamento estratégico adotado por empresas fabris de pequeno porte no nível de utilização das práticas gerenciais. Acerca disso, convém salientar que a associação do posicionamento estratégico ao ambiente de atuação da organização é aventado por Porter (1991) quando este afirma que a estratégia a ser adotada deverá ser escolhida a partir da análise das forças competitivas de mercado que irão compor o ambiente de atuação da organização (também conhecido como Escola do Posicionamento), cabendo escolher entre as estratégias genéricas de competição "custo baixo", "diferenciação" e "enfoque". Entretanto, nesta pesquisa tais estratégias são tratadas como tipos de posicionamento estratégico, porque é após analisar-se as forças competitivas do segmento de atuação das organizações que estas devem se posicionar a fim de responder a essas forças, optando por uma estratégia baseada 
em custos baixos ou na diferenciação, sendo que ambas podem ter um escopo amplo ou estreito (Porter, 1991).

Nesse rumo, considerou-se que a estratégia de diferenciação se refere ao posicionamento da organização em relação aos concorrentes, à imagem da marca e ao relacionamento com o públicoalvo, entre outros aspectos discutidos na literatura a respeito (Porter, 1991). Por outro lado, a estratégia de custos baixos assume que as organizações que optam por esse caminho devem ter alta participação de mercado, acesso mais favorável às matérias-primas ou suprimentos, comercializar mercadorias de fácil produção ou aquisição, possuir ampla linha de produtos afins e dispor de uma base de clientes extensa. Desse modo, deve perseguir grandes nichos de mercado e ser capaz de gerar alto valor de lucro com a venda de grandes quantidades de produtos e/ou serviços (Porter, 1991).

Junqueira et al. (2016) mencionam que essas duas estratégias genéricas também podem ser aplicadas num contexto restrito, quando são conhecidas por "enfoque" ou "foco". Nesses casos, a empresa escolhe trabalhar com determinado tipo de cliente, linha de produto ou espaço geográfico, de forma a selecionar um público específico em um pequeno segmento de mercado.

Quanto à seleção das práticas gerenciais a serem consideradas na pesquisa, Almeida e Callado (2018) argumentam que, diante da diversidade destas na literatura de Contabilidade Gerencial e das possibilidades de utilização pelas empresas, é pertinente definir um rol específico para integrar determinado estudo. Assim, nesta pesquisa foi priorizada a proposição da International Federation of Accountants (Ifac) (1998), que segrega o desenvolvimento da contabilidade gerencial em quatro estágios evolutivos e está alinhada com as pesquisas de Abdel-Kader e Luther (2008), que também segregaram as práticas de contabilidade gerencial em quatro estágios. Nesse sentido, entre as diversas publicações recentes que optaram por utilizar essa divisão em quatro estágios estão: Valeriano (2012); Abdel Al e Mclellan (2013); Leite (2013); Ahmad (2014); Mclellan (2014); Leite, Diehl e Manvailer (2015); Dalchiavon, Wernke e Zanin (2017); Rufatto (2018); e Santos, Corrêa, Beuren e Gomes (2019). Entretanto, a depender do estudo analisado, são encontradas pequenas diferenças entre as práticas classificáveis nos quatro estágios, com adições ou exclusões conforme tais autores.

No que tange ao fator contingencial visado, o aspecto utilizado neste estudo foi o número de funcionários das empresas abrangidas, que serviu para classificá-las em dois grupos quanto ao porte (pequenas e microempresas). A opção por este critério deveu-se ao fato de que possivelmente não haveria restrições a respeito da divulgação desse dado pelos participantes do estudo, bem como por ter sido adotado em estudos precedentes (Leite, Diehl, \& Manvailer, 2015; Siska, 2016; Callado, 2016; Maletic et al., 2017; Klein \& Almeida, 2017; Almeida \& Callado, 2018; Rufatto, 2018).

Quanto à hipótese aventada, esta versou acerca de duas categorias de empresa: $(i)$ indústrias adotantes do posicionamento estratégico da "diferenciação" e (ii) fábricas optantes pela estratégia genérica de "custo baixo". A partir disso foi cogitado que o nível de utilização das práticas de gestão financeira é igual nas empresas de pequeno porte, independentemente do posicionamento estratégico adotado (hipótese nula). Então, por levar em conta o posicionamento estratégico, as práticas gerenciais e empresas de pequeno porte, o constructo da suposição em lume teve a fundamentação teórica apresentada na Figura 1.

\begin{tabular}{|l|l|}
\hline \multicolumn{1}{|c|}{ Aspectos } & \multicolumn{1}{c|}{ Fundamentação teórica } \\
\hline Posicionamento estratégico & Porter (1991); Otley (2016); Junqueira et al. (2016); Almeida e Callado (2018) \\
\hline Práticas gerenciais & $\begin{array}{l}\text { Ifac (1998); Valeriano (2012); Ahmad (2014); Leite, Diehl e Manvailer (2015); Rufatto } \\
\text { (2018); Santos } \text { et al. (2019). }\end{array}$ \\
\hline Porte da empresa & Maletic et al. (2017); Klein e Almeida (2017); Almeida e Callado (2018) \\
\hline
\end{tabular}

Figura 1. Constructo da pesquisa

Fonte: Elaborada pelos autores. 


\section{PROCEDIMENTOS METODOLÓGICOS}

Quanto aos aspectos metodológicos, em relação à tipologia do objetivo cabe classificá-la como descritiva, pois para Andrade (2002) os estudos descritivos se preocupam em observar os fatos, registrá-los, analisá-los, classificá-los e interpretá-los sem a interferência direta do pesquisador no contexto.

No que tange à forma de abordagem, a presente pesquisa se enquadra como quantitativa, visto que Richardson (1999) aduz que essa modalidade envolve os estudos que empregam a quantificação, tanto nas modalidades de coleta de informações quanto no tratamento destas por meio de técnicas estatísticas, desde as mais simples (como percentual, média, desvio padrão etc.) até aquelas mais complexas (como coeficientes de correlação, análises de regressão etc.).

Em termos dos procedimentos para coligir os dados foi escolhida a técnica do levantamento ou survey (Gil, 2010), instrumentalizada por intermédio de questionário aplicado aos participantes entre os meses de maio e julho de 2018. O referido instrumento foi composto por questões embasadas na Teoria da Contingência (Donaldson, 2001; Chenhall \& Chapman, 2006), na análise do posicionamento estratégico defendido por Porter (1991) e nas ferramentas gerenciais financeiras elencadas pela Ifac (1998).

Quanto ao formato das perguntas, além das questões que captavam as características das empresas participantes, nas partes referentes ao posicionamento estratégico e às práticas gerenciais abrangidas o questionário continha questões com cinco alternativas de resposta (1 - Discordo totalmente; 2 - Discordo parcialmente; 3 - Indiferente/Neutro; 4 - Concordo parcialmente; e 5 Concordo totalmente), cujo tipo de escala pode ser classificado como pertencente ao padrão tradicionalmente denominado Likert (Dalmoro \& Vieira, 2013).

Os questionários aplicados foram preenchidos on-line (na ferramenta Google Forms) a partir das informações coligidas dos gestores de empresas fabris. Estes foram contatados por intermédio das associações empresariais da região geográfica selecionada, mediante envio de e-mail contendo o link do formulário respectivo, bem como de modo presencial por um grupo de alunos treinados para essa finalidade pelos autores.

Em relação ao corpus da pesquisa, esta abrangeu amostra que totalizou 88 participantes e foi extraída da população composta pelas pequenas empresas industriais da microrregião da Amurel cujos gestores concordaram em participar. Portanto, a abrangência se adequou ao critério de acessibilidade por parte dos pesquisadores. Ainda, como critérios para participar da pesquisa foram selecionadas as características de (i) ser empresa fabril com até 100 funcionários e (ii) estar sediada na microrregião da Amurel.

No que concerne à análise dos dados, primeiramente esses dados foram tabulados em planilha Excel, onde foi empregada a estatística descritiva (frequência e número de respostas) para sintetizar os resultados e facilitar a interpretação dos "achados" do estudo. Em seguida, para verificar a normalidade dos dados foram utilizados os testes Kolmogorov-Smirnov e Shapiro-Wilk, conforme avaliação extraída do software Statistical Package for Social Sciences (SPSS). Pelo padrão das respostas obtidas foi possível aplicar o teste não paramétrico Mann-Whitney, que é recomendado para análise de duas amostras independentes (neste caso, uma que envolve as empresas que adotam a estratégia genérica de "diferenciação" e outra para as que utilizam a estratégia de "custo baixo"), que serve como uma alternativa ao T-Test e fundamenta sua análise em médias dos grupos (Rauen, 2015; Bruni, 2012; Triola, 2005).

Esse teste foi aplicado para verificar hipótese acerca dos dois grupos de indústrias abrangidas (adotantes do posicionamento estratégico da "diferenciação" versus os adotantes do "custo baixo"), 
ou seja: o nível de utilização das práticas de gestão financeira é igual nas empresas de pequeno porte, independentemente do posicionamento estratégico adotado (hipótese nula). Convém salientar também que os resultados oriundos do teste de Mann-Whitney devem ser interpretados da seguinte forma: $(i)$ se "Sig > 0,05", não se pode rejeitar a hipótese nula (H0), aceitando-se o fato da existência de igualdade entre os grupos testados e (ii) se "Sig < 0,05", refuta-se a hipótese nula (H0), cabendo rejeitar-se o fato de existir igualdade entre os grupos abrangidos (Bruni, 2012).

\section{APRESENTAÇÃO DOS DADOS E DISCUSSÃO DOS RESULTADOS}

As próximas seções apresentam os principais aspectos relacionados às empresas pesquisadas, aos dados coletados e aos resultados oriundos do estudo.

\subsection{Características dos respondentes e das empresas}

As respostas coligidas permitiram conhecer o perfil dos 88 respondentes e das respectivas indústrias. No caso dos respondentes, foram averiguadas características como "tipo de vínculo com a empresa", "tempo de atuação na função atual", "nível de escolaridade", "curso de graduação" e "curso de pós-graduação”. Quanto às características das empresas abrangidas pelo estudo, apurou-se o seguinte cenário:

1) Ramo de atividade: a respeito dessa característica, as respostas identificaram que a maior concentração ocorreu no segmento de "confecção de artigos do vestuário e acessórios" (14,77\%), "alimentícios" (13,64\%), "borracha e material plástico" (11,36\%) e "metalurgia" $(6,82 \%)$. Além desses, algumas empresas classificavam-se como indústrias de "máquinas e equipamentos", "móveis", "bebidas", “madeira", "químicos", "minerais não-metálicos", "produtos de limpeza/higiene pessoal", "têxteis (exceto confecções)" e "outros tipos de indústria".

2) Configuração tributária: os optantes pelo "Simples" formaram o maior grupo (com 67,55\% do total) e foram seguidos pelas empresas que escolheram o lucro presumido $(17,05 \%)$ e o lucro real $(15,91 \%)$.

3) Tipo de empresa: a formatação predominante foi a de empresas "limitada" (sociedades por quotas de responsabilidade limitada), com 69,32\% das participantes. O segundo maior grupo foi composto pelas empresas individuais de responsabilidade limitada (Eireli), com 15,91\% do total de respostas, e o terceiro conjunto foi formado pelos microempreendedores individuais (MEI), pois as 13 empresas dessa categoria representaram $14,77 \%$ do conjunto pesquisado.

4) Quantidade de empregados: 58 das entidades participantes (65,91\% do total) possuem entre 20 e 99 funcionários (pequenas empresas), enquanto 26 indústrias (equivalente a 29,55\%) têm até 19 funcionários (microempresas) e somente 4 contavam apenas com o trabalho do proprietário $(4,55 \%)$.

\subsection{Aspectos da gestão estratégica das empresas pesquisadas}

Quanto aos dados coligidos em relação à gestão estratégica, a realidade encontrada está sintetizada na Tabela 1 . 
Tabela 1

\section{Aspectos da gestão estratégica}

\begin{tabular}{|c|c|c|c|}
\hline Itens & $\begin{array}{l}\text { Discorda total ou } \\
\text { parcialmente }(\%)\end{array}$ & $\begin{array}{r}\text { Indiferente ou } \\
\text { neutro }(\%)\end{array}$ & $\begin{array}{l}\text { Concorda total ou } \\
\text { parcialmente }(\%)\end{array}$ \\
\hline $\begin{array}{l}\text { Consegue descontos nas compras (poder de barganha com } \\
\text { fornecedores) }\end{array}$ & 3,41 & 5,68 & 90,91 \\
\hline $\begin{array}{l}\text { Consegue impor preços aos clientes (poder de barganha com } \\
\text { clientela) }\end{array}$ & 18,18 & 9,09 & 72,73 \\
\hline Percebe barreiras de entrada para novos concorrentes no segmento & 37,50 & 19,32 & 43,18 \\
\hline Novos entrantes são comuns no segmento & 27,27 & 10,23 & 62,50 \\
\hline Há ameaça de novos produtos ou substitutos & 34,09 & 14,77 & 51,14 \\
\hline Há grande rivalidade entre concorrentes do segmento & 14,77 & 12,50 & 72,73 \\
\hline Estratégia adotada é de diferenciação & 20,45 & 13,64 & 65,91 \\
\hline Estratégia adotada é de preços/custos baixos & 44,32 & 21,59 & 34,09 \\
\hline $\begin{array}{l}\text { Estratégia adotada é enfoque (escolha por competir em nichos de } \\
\text { mercado) }\end{array}$ & 72,73 & 27,27 & - \\
\hline Gastos com propaganda são prioridade estratégica & 45,45 & 19,32 & 35,23 \\
\hline Investimentos para redução de custos são prioridade estratégica & 9,09 & 18,18 & 72,73 \\
\hline Pesquisas e desenvolvimento de produtos são prioridade estratégica & 23,86 & 28,41 & 47,73 \\
\hline $\begin{array}{l}\text { Serviços pós-venda e atendimento a clientes são prioridade } \\
\text { estratégica }\end{array}$ & 25,00 & 23,86 & 51,14 \\
\hline Diferenciação de produtos/serviços são prioridade estratégica & 17,05 & 21,59 & 61,36 \\
\hline $\begin{array}{l}\text { Pesquisas de mercado com clientes sobre inovações são prioridade } \\
\text { estratégica }\end{array}$ & 21,59 & 20,45 & 57,95 \\
\hline
\end{tabular}

Fonte: Elaborada pelos autores.

Constatou-se, então, que a maioria das empresas pesquisadas $(90,91 \%)$ consegue obter descontos dos fornecedores nas compras cotidianas, o que pode ser considerado um resultado inesperado em razão do pequeno porte das entidades participantes deste estudo. Por outro ângulo, a maior parte dos respondentes $(72,73 \%)$ afirmou que consegue impor preços de venda aos clientes (ou seja, possui poder de barganhar com a clientela).

Quanto ao aspecto da concorrência, somente 43,18\% concordam que há barreiras de entrada para novos concorrentes, mas $62,50 \%$ afirmaram que comumente há novos entrantes no segmento em que atuam, enquanto $51,14 \%$ observam a existência de produtos novos ou substitutos no mercado. Esses dados podem ser uma justificativa para o fato de que $72,73 \%$ das empresas pesquisadas consideram que existe grande rivalidade entre os concorrentes.

No que concerne à estratégia adotada, quase dois terços $(65,91 \%)$ informaram que priorizam o posicionamento de "diferenciação" e 34,09\% preferem o caminho dos "custos baixos". Portanto, não houve manifestação de uso do "enfoque" (atuação em nichos de mercado) como opção estratégica.

A opção pela "diferenciação" se coaduna com as respostas às questões ligadas com a priorização de pesquisa e desenvolvimento de produtos (por 47,73\% das pequenas indústrias pesquisadas), prestação de serviços pós-venda e atendimento a clientes $(51,14 \%)$, busca pela 
diferenciação de produtos/serviços $(61,36 \%)$ e a pesquisa de mercado com clientes acerca de inovações $(57,95 \%)$. Contudo, contradiz parcialmente com o reduzido gasto com propaganda (priorizado por 35,23\% das empresas) e, em especial, pela priorização de investimentos para redução de custos (pretendida por $72,73 \%$ das entidades).

\subsection{Práticas gerenciais adotadas}

As questões apresentadas aos participantes relacionadas com as práticas gerenciais foram divididas levando-se em conta os estágios preconizados pela Ifac (1998), conforme evidenciado na sequência.

Acerca das práticas do primeiro estágio, os resultados apurados estão listados na Tabela 2.

Tabela 2

\section{Práticas gerenciais adotadas - Estágio 1}

\begin{tabular}{lccc}
\hline Itens & $\begin{array}{r}\text { Discorda total ou } \\
\text { parcialmente (\%) }\end{array}$ & $\begin{array}{r}\text { Indiferente ou } \\
\text { neutro (\%) }\end{array}$ & $\begin{array}{r}\text { Concorda total ou } \\
\text { parcialmente (\%) }\end{array}$ \\
\hline Análise do retorno s/ investimento & 12,50 & 18,18 & 69,32 \\
Método de custeio por absorção & 23,86 & 30,68 & 45,45 \\
Método de custeio direto & 21,59 & 26,14 & 52,27 \\
Método de custeio padrão & 15,91 & 29,55 & 54,55 \\
Método de custeio variável & 18,18 & 23,86 & 57,95 \\
Média das práticas do estágio 1 & 18,41 & 25,68 & 55,91 \\
\hline
\end{tabular}

Fonte: Elaborada pelos autores.

No caso das cinco práticas relacionadas ao Estágio 1, a média das respostas que concordam total ou parcialmente com utilização destas pelos gestores pesquisados ficou no patamar de 55,91\%. Destas, a que mais se destacou foi a análise do retorno sobre o investimento (com 69,32\% das empresas utilizando-a) e aquela com menor nível de adoção $(45,45 \%)$ foi o método de custeio por absorção.

Tabela 3 .

Quando foram abordadas as práticas do segundo estágio foi apurado o cenário sintetizado na

Tabela 3

Práticas gerenciais adotadas - Estágio 2

\begin{tabular}{lrrr}
\hline Itens & $\begin{array}{r}\text { Discorda total ou } \\
\text { parcialmente (\%) }\end{array}$ & $\begin{array}{r}\text { Indiferente ou } \\
\text { neutro (\%) }\end{array}$ & $\begin{array}{r}\text { Concorda total ou } \\
\text { parcialmente (\%) }\end{array}$ \\
\hline Análise de custo-volume-lucro & 7,95 & 17,05 & 75,00 \\
Análise do valor presente & 11,36 & 20,45 & 68,18 \\
Avaliação do desempenho & 12,50 & 12,50 & 75,00 \\
Controles internos para proteção de ativos & 14,77 & 17,05 & 68,18 \\
Planejamento tributário & 13,64 & 13,64 & 72,73 \\
Preço de transferência & 21,59 & 20,45 & 57,95 \\
Orçamento de capital & 17,05 & 18,18 & 64,77 \\
Orçamento operacional & 10,23 & 17,05 & 72,73 \\
Média das práticas do estágio 2 & 13,64 & 17,05 & 69,32 \\
\hline
\end{tabular}

Fonte: Elaborada pelos autores. 
Com média de utilização superior àquela verificada no âmbito do primeiro estágio, as oito práticas deste grupo alcançaram o nível médio de 69,32\%. Nesse sentido, é válido ressaltar as quatro práticas que superaram esse patamar: análise custo-volume-lucro (CVL) e avaliação do desempenho (ambas com $75 \%$ de respostas positivas) e planejamento tributário e orçamento operacional (as duas com $72,73 \%$ de concordância sobre a utilização).

No que tange às práticas gerenciais enquadradas no terceiro estágio, a realidade apurada está deslindada na Tabela 4.

Tabela 4

Práticas gerenciais adotadas - Estágio 3

\begin{tabular}{lccc}
\hline Itens & $\begin{array}{c}\text { Discorda total ou } \\
\text { parcialmente (\%) }\end{array}$ & $\begin{array}{c}\text { Indiferente ou } \\
\text { neutro (\%) }\end{array}$ & $\begin{array}{c}\text { Concorda total ou } \\
\text { parcialmente }(\%)\end{array}$ \\
\hline Análise da terceirização & 21,59 & 25,00 & 53,41 \\
Open book accounting & 34,09 & 40,91 & 25,00 \\
Método de custeio ABC/TDABC* & 21,59 & 37,50 & 40,91 \\
Método de custeio Kaizen & 36,36 & 34,09 & 29,55 \\
Método de custeio Meta & 27,27 & 21,59 & 51,14 \\
Média das práticas do estágio 3 & 28,18 & 31,82 & 40,00 \\
\hline
\end{tabular}

Nota. ${ }^{*}$ Activity-based costing/time-driven activity-based costing (custeio baseado em atividades e tempo).

Fonte: Elaborada pelos autores.

Portanto, constatou-se que a média das respostas que concordam (total ou parcialmente) com a utilização dessas práticas nas empresas abrangidas ficou em $40 \%$. Isso implica considerar que tal agrupamento de práticas foi o que teve menores níveis de adoção pelos gestores na comparação com os outros três estágios. Nesse rol, o item que mais se destacou foi a análise da terceirização, pois recebeu 53,41\% de respostas no sentido de sua utilização nas pequenas indústrias do estudo.

Acerca das práticas do quarto estágio, as respostas obtidas permitiram elaborar a Tabela 5, que resume o cenário encontrado.

Tabela 5

\section{Práticas gerenciais adotadas - Estágio 4}

\begin{tabular}{|c|c|c|c|}
\hline Itens & $\begin{array}{l}\text { Discorda total ou } \\
\text { parcialmente }(\%)\end{array}$ & $\begin{array}{r}\text { Indiferente ou } \\
\text { neutro }(\%)\end{array}$ & $\begin{array}{l}\text { Concorda total ou } \\
\text { parcialmente }(\%)\end{array}$ \\
\hline Análise da cadeia de valor & 23,86 & 30,68 & 45,45 \\
\hline Balanced scorecard & 25,00 & 31,82 & 43,18 \\
\hline Gestão baseada em valor & 17,05 & 30,68 & 52,27 \\
\hline Gestão interorganizacional de custos & 15,91 & 27,27 & 56,82 \\
\hline Indicadores-chave de performance (KPIs) & 19,32 & 31,82 & 48,86 \\
\hline Sistema de gestão econômica (GECON) & 26,14 & 37,50 & 36,36 \\
\hline Teoria das restrições (TOC) & 22,73 & 44,32 & 32,95 \\
\hline Valor econômico adicionado (EVA) & 22,73 & 37,50 & 39,77 \\
\hline Média das práticas do estágio 4 & 21,59 & 33,95 & 44,46 \\
\hline
\end{tabular}

Fonte: Elaborada pelos autores. 
Com a segunda menor média de adoção $(44,46 \%)$ entre os quatro estágios citados, neste grupo somente duas práticas superaram o patamar de 50\%: gestão baseada em valor (com 52,27\% das respostas concordando com a utilização nas empresas) e gestão interorganizacional de custos (com $56,82 \%)$. Todas as demais práticas do estágio 4 são adotadas por menos da metade das indústrias em tela.

\subsection{Teste estatístico U de Mann-Whitney}

Com o fito de obter subsídios estatísticos para fundamentar as conclusões acerca da hipótese de pesquisa cogitada foi aplicado o teste de Mann-Whitney, cujos resultados estão deslindados na Tabela 6.

Tabela 6

\section{Teste de Mann-Whitney do posicionamento estratégico versus práticas gerenciais}

\begin{tabular}{|c|c|c|c|c|c|c|}
\hline Práticas gerenciais & $\begin{array}{c}\text { Posic. } \\
\text { estratégico }\end{array}$ & $\mathrm{N}$ & $\begin{array}{c}\text { Mean } \\
\text { rank }\end{array}$ & $\begin{array}{c}\text { Mann- } \\
\text { Whitney U }\end{array}$ & Z & $\begin{array}{c}\text { Valor-p } \\
\text { ( } 2 \text { caudas) }\end{array}$ \\
\hline E1 Análise do retorno sobre investimento & $\begin{array}{c}\text { Diferenc. } \\
\text { Custo }\end{array}$ & $\begin{array}{l}58 \\
30 \\
\end{array}$ & $\begin{array}{l}46,75 \\
40,15 \\
\end{array}$ & 739,50 & $-1,2433$ & 0,2138 \\
\hline E1 Custeio por absorção & $\begin{array}{c}\text { Diferenc. } \\
\text { Custo }\end{array}$ & $\begin{array}{l}58 \\
30 \\
\end{array}$ & $\begin{array}{l}42,97 \\
47,45 \\
\end{array}$ & 781,50 & $-0,8215$ & 0,4113 \\
\hline E1 Custeio direto & $\begin{array}{c}\text { Diferenc. } \\
\text { Custo }\end{array}$ & $\begin{array}{l}58 \\
30 \\
\end{array}$ & $\begin{array}{l}45,81 \\
41,97 \\
\end{array}$ & 794,00 & $-0,7085$ & 0,4786 \\
\hline E1 Custeio padrão & $\begin{array}{c}\text { Diferenc. } \\
\text { Custo }\end{array}$ & $\begin{array}{l}58 \\
30 \\
\end{array}$ & $\begin{array}{l}47,17 \\
39,33 \\
\end{array}$ & 715,00 & $-1,4232$ & 0,1547 \\
\hline E1 Custeio variável & $\begin{array}{c}\text { Diferenc. } \\
\text { Custo }\end{array}$ & $\begin{array}{l}58 \\
30 \\
\end{array}$ & $\begin{array}{l}46,68 \\
40,28 \\
\end{array}$ & 743,50 & - 1,1956 & 0,2319 \\
\hline E2 Análise CVL & $\begin{array}{c}\text { Diferenc. } \\
\text { Custo }\end{array}$ & $\begin{array}{l}58 \\
30 \\
\end{array}$ & $\begin{array}{l}47,42 \\
38,85 \\
\end{array}$ & 700,50 & $-1,6207$ & 0,1051 \\
\hline E2 Análise do valor presente & $\begin{array}{l}\text { Diferenc. } \\
\text { Custo }\end{array}$ & $\begin{array}{l}58 \\
30 \\
\end{array}$ & $\begin{array}{l}47,71 \\
38,30 \\
\end{array}$ & 684,00 & $-1,7308$ & 0,0835 \\
\hline E2 Avaliação do desempenho & $\begin{array}{l}\text { Diferenc. } \\
\text { Custo }\end{array}$ & $\begin{array}{l}58 \\
30 \\
\end{array}$ & $\begin{array}{l}46,94 \\
39,78 \\
\end{array}$ & 728,50 & $-1,3207$ & 0,1866 \\
\hline E2 Controle interno para proteção dos ativos & $\begin{array}{c}\text { Diferenc. } \\
\text { Custo }\end{array}$ & $\begin{array}{l}58 \\
30 \\
\end{array}$ & $\begin{array}{l}45,54 \\
42,48 \\
\end{array}$ & 809,50 & $-0,5607$ & 0,5750 \\
\hline E2 Planejamento tributário & $\begin{array}{c}\text { Diferenc. } \\
\text { Custo }\end{array}$ & $\begin{array}{l}58 \\
30 \\
\end{array}$ & $\begin{array}{l}49,25 \\
35,32 \\
\end{array}$ & 594,50 & $-2,5751$ & $0,0100 *$ \\
\hline E2 Preço de transferência & $\begin{array}{l}\text { Diferenc. } \\
\text { Custo }\end{array}$ & $\begin{array}{l}58 \\
30 \\
\end{array}$ & $\begin{array}{l}45,49 \\
42,58 \\
\end{array}$ & 812,50 & $-0,5266$ & 0,5985 \\
\hline E2 Orçamento de capital & $\begin{array}{l}\text { Diferenc. } \\
\text { Custo }\end{array}$ & $\begin{array}{l}58 \\
30 \\
\end{array}$ & $\begin{array}{l}47,22 \\
39,25 \\
\end{array}$ & 712,50 & $-1,4476$ & 0,1477 \\
\hline E2 Orçamento operacional & $\begin{array}{l}\text { Diferenc. } \\
\text { Custo }\end{array}$ & $\begin{array}{l}58 \\
30 \\
\end{array}$ & $\begin{array}{l}46,07 \\
41,47 \\
\end{array}$ & 779,00 & $-0,8455$ & 0,3978 \\
\hline E3 Análise da terceirização & $\begin{array}{l}\text { Diferenc. } \\
\text { Custo }\end{array}$ & $\begin{array}{l}58 \\
30 \\
\end{array}$ & $\begin{array}{l}45,40 \\
42,77 \\
\end{array}$ & 818,00 & $-0,4727$ & 0,6364 \\
\hline E3 Open book accounting & $\begin{array}{l}\text { Diferenc. } \\
\text { Custo }\end{array}$ & $\begin{array}{l}58 \\
30 \\
\end{array}$ & $\begin{array}{l}46,81 \\
40,03\end{array}$ & 736,00 & $-1,2367$ & 0,2162 \\
\hline E3 Custeio ABC/TDABC & $\begin{array}{l}\text { Diferenc. } \\
\text { Custo }\end{array}$ & $\begin{array}{l}58 \\
30 \\
\end{array}$ & $\begin{array}{l}45,78 \\
42,02\end{array}$ & 795,50 & $-0,6837$ & 0,4941 \\
\hline
\end{tabular}




\begin{tabular}{|c|c|c|c|c|c|c|}
\hline E3 Custeio Kaizen & $\begin{array}{c}\text { Diferenc. } \\
\text { Custo }\end{array}$ & $\begin{array}{l}58 \\
30 \\
\end{array}$ & $\begin{array}{l}44,91 \\
43,70 \\
\end{array}$ & 846,00 & $-0,2190$ & 0,8267 \\
\hline E3 Custeio Meta & $\begin{array}{c}\text { Diferenc. } \\
\text { Custo }\end{array}$ & $\begin{array}{l}58 \\
30 \\
\end{array}$ & $\begin{array}{l}47,91 \\
37,90 \\
\end{array}$ & 672,00 & $-1,8251$ & 0,0680 \\
\hline E4 Análise da cadeia de valor & $\begin{array}{c}\text { Diferenc. } \\
\text { Custo }\end{array}$ & $\begin{array}{l}58 \\
30 \\
\end{array}$ & $\begin{array}{l}48,08 \\
37,58\end{array}$ & 662,50 & $-1,8902$ & 0,0587 \\
\hline E4 Balanced scorecard & $\begin{array}{c}\text { Diferenc. } \\
\text { Custo }\end{array}$ & $\begin{array}{l}58 \\
30 \\
\end{array}$ & $\begin{array}{l}46,31 \\
41,00 \\
\end{array}$ & 765,00 & $-0,9540$ & 0,3401 \\
\hline E4 Gestão baseada em valor & $\begin{array}{c}\text { Diferenc. } \\
\text { Custo }\end{array}$ & $\begin{array}{l}58 \\
30 \\
\end{array}$ & $\begin{array}{l}46,18 \\
41,25\end{array}$ & 772,50 & $-0,8915$ & 0,3727 \\
\hline E4 Gestão interorganizacional de custos & $\begin{array}{c}\text { Diferenc. } \\
\text { Custo }\end{array}$ & $\begin{array}{l}58 \\
30 \\
\end{array}$ & $\begin{array}{l}46,22 \\
41,17 \\
\end{array}$ & 770,00 & $-0,9169$ & 0,3592 \\
\hline E4 Indicadores-chave de performance (KPIs) & $\begin{array}{c}\text { Diferenc. } \\
\text { Custo }\end{array}$ & $\begin{array}{l}58 \\
30 \\
\end{array}$ & $\begin{array}{l}48,41 \\
36,95 \\
\end{array}$ & 643,50 & $-2,0678$ & $0,0387^{*}$ \\
\hline E4 Sistema de gestão econômica (GECON) & $\begin{array}{c}\text { Diferenc. } \\
\text { Custo }\end{array}$ & $\begin{array}{l}58 \\
30 \\
\end{array}$ & $\begin{array}{l}45,26 \\
43,03 \\
\end{array}$ & 826,00 & $-0,4034$ & 0,6867 \\
\hline E4 Teoria das restrições (TOC) & $\begin{array}{c}\text { Diferenc. } \\
\text { Custo }\end{array}$ & $\begin{array}{l}58 \\
30 \\
\end{array}$ & $\begin{array}{l}47,16 \\
39,37\end{array}$ & 716,00 & $-1,4372$ & 0,1507 \\
\hline E4 Valor econômico adicionado (EVA) & $\begin{array}{c}\text { Diferenc. } \\
\text { Custo }\end{array}$ & $\begin{array}{l}58 \\
30 \\
\end{array}$ & $\begin{array}{l}47,74 \\
38,23 \\
\end{array}$ & 682,00 & $-1,7283$ & 0,0839 \\
\hline
\end{tabular}

Nota. * Valor estatisticamente significativo.

Fonte: Elaborada pelos autores.

Quanto aos resultados identificados no caso das práticas gerenciais do primeiro estágio, assumiu-se que a hipótese nula (H0) cogitava que o nível de utilização dos cinco integrantes seria igual entre as pequenas indústrias em tela, independentemente do posicionamento estratégico. Nesse sentido, em relação à variável "E1-Análise do retorno sobre investimentos" os valores de posto médio (mean rank) para os dois grupos de empresas foram de 46,75 para o Grupo 1 - Diferenciação e chegou a 40,15 no Grupo 2 - Custos. O teste de hipóteses apresentou uma estatística Z igual a - 1,2433, com nível de significância de 0,2138. Esse resultado indica a aceitação da hipótese nula (H0) e a rejeição da hipótese alternativa (H1), o que recomenda considerar que as médias dos dois grupos sejam semelhantes. Resultados assemelhados também foram apurados em relação às práticas "E1-Custeio por absorção" (com Z = - 0,8215 e Sig. = 0,4113), "E1-Custeio direto" $(Z=-0,7085$ e Sig. = 0,4786), "E1-Custeio padrão" $(Z=-1,4232$ e Sig. $=0,1547)$ e "E1-Custeio variável $(Z=-1,1956$ e Sig. $=0,2319)$.

Ao abranger as práticas gerenciais do segundo estágio foi constatado que, em relação à variável "E2-Análise CVL", os valores de posto médio (mean rank) para os dois grupos de empresas foram de 47,42 para o Grupo 1 - Diferenciação e chegou a 38,85 no âmbito do Grupo 2 - Custos. Além disso, o teste de hipóteses apresentou uma estatística Z igual a - 1,6207, com nível de significância de 0,1051. Desse modo, então, é cabível aceitar a hipótese nula (H0), que considera que as médias dos dois grupos sejam semelhantes. Resultados assemelhados também foram apurados no caso das práticas "E2Análise do valor presente" (com $Z=-1,7308$ e Sig. =0,0835), "E2-Avaliação do desempenho" $(Z=-1,3207$ e Sig. =0,1866), "E2-Controles internos para proteção de ativos" $(Z=-0,5607$ e Sig. =0,5750), "E2- Preço de transferência" $(Z=-0,5266$ e Sig. =0,5985), "E2-Orçamento de capital" ( $Z=-1,4476$ e Sig. = 0,1477) e "E2-Orçamento operacional" $(Z=-0,8455$ e Sig. = 0,3978). Porém, somente no caso da variável "E2-Planejamento tributário" é que foi constatado nível de significância (Sig. = 0,0100) suficiente para rejeitar a hipótese nula e aceitar o fato de existir diferença 
entre os dois grupos abrangidos.

Quando analisadas as práticas gerenciais do terceiro estágio, no caso da "E3-Análise da terceirização" restou evidenciado que os valores de posto médio (mean rank) para os dois grupos de empresas foram de 45,40 para o Grupo 1 - Diferenciação e chegou a 42,77 no âmbito do Grupo 2 Custos. No que tange ao teste de hipóteses, este apresentou uma estatística Z igual a - 0,4727, com nível de significância de 0,6364. Portanto, indica que cabe aceitar a hipótese nula (H0) e sugere que as médias dos dois grupos são estatisticamente assemelhadas. Essa mesma conclusão se aplica em relação às práticas "E3-Open book accounting" (com $\mathrm{Z}=-1,2367$ e Sig. = 0,2162), "E3-Custeio ABC/TDABC" $(Z=0,6837$ e Sig. = 0,4941), "E3-Custeio Kaizen" $(Z=-0,2190$ e Sig. = 0,8267) e "E3-Custeio meta" $(Z=-1,8251$ e Sig. = 0,0680).

Por último, ao avaliar os resultados do teste estatístico das práticas gerenciais do quarto estágio, no que se refere à prática "E4-Análise da cadeia de valor" foi apurado que os valores de posto médio (mean rank) para os dois grupos de empresas foram de 48,08 para o Grupo 1 - Diferenciação e chegou a 37,58 no âmbito do Grupo 2 - Custos. O teste de hipóteses apresentou estatística Z igual a - 1,8902, com nível de significância de 0,0587. Esse resultado indica a aceitação da hipótese nula (H0) e a rejeição da hipótese alternativa $(\mathrm{H} 1)$, o que recomenda considerar que as médias dos dois grupos sejam semelhantes. Resultado semelhante também foi obtido em relação às práticas "E4Balanced scorecard" (com $Z=-0,9540$ e Sig. =0,3401), "E4-Gestão baseada em valor" $(Z=-0,8915$ e Sig. =0,3727), "E4-Gestão interorganizacional de custos" $(Z=-0,9169$ e Sig. = 0,3592), "E4-Sitema de gestão econômica (GECON)" $(Z=-0,4034$ e Sig. = 0,6867), "E4Teoria das restrições (TOC)" $(Z=-1,4372$ e Sig. $=0,1507)$ e "E4-Valor econômico adicionado (EVA)" $(Z=-1,7283$ e Sig. = 0,0839). Contudo, somente no caso da variável "E4-Indicadores-chave de performance (KPIs)" é que foi constatado nível de significância (Sig. = 0,0387) suficientemente forte para rejeitar a hipótese nula e aceitar o fato de existir diferença entre os dois grupos abrangidos.

\subsection{Análise e cotejamento dos resultados}

Os níveis de utilização por estágios, com prioridade para as práticas do primeiro e segundo estágios (como verificado neste estudo), estão alinhados aos resultados de pesquisas precedentes. Nesse sentido, Almeida e Callado (2018) comentam que a literatura de Contabilidade Gerencial sinaliza o predomínio de práticas de contabilidade gerencial tradicionais, em detrimento daquelas consideradas avançadas, como encontrado nos estudos de Chenhall e Langfield-Smith (1998) na Austrália, Joshi (2001) na Índia, Sulaiman, Ahmad e Alwi (2004) em países asiáticos, Abdel-Kader e Luther (2006) no Reino Unido, e Pavlatos e Paggios (2009) na Grécia. Idem para o caso relatado por Almeida e Callado (2018), em que uma empresa gráfica da Paraíba também priorizava a utilização de práticas associadas ao primeiro e segundo estágios.

De forma assemelhada, ao pesquisarem 23 indústrias paranaenses com o propósito de investigar se a adoção de práticas de contabilidade gerencial seria afetada por fatores contingenciais, Klein e Almeida (2017) dessumiram que há uma maior utilização dos instrumentos gerenciais tradicionais em detrimento de técnicas mais sofisticadas integrantes de estágios mais evoluídos. Por sua vez, Panosso, Camanho, Espejo e Abbas (2017) concluíram que as ferramentas com maior nível de utilização por 149 empresas industriais filiadas à Federação das Indústrias do Estado do Paraná (Fiep) são "orçamento operacional" e "análise de lucratividade", que também são enquadráveis no segundo estágio da classificação da Ifac (1998).

Quanto à pesquisa de Junqueira et al. (2016), que abordou o tema de forma mais assemelhada ao foco escolhido nesta pesquisa, convém ressaltar que investigou o efeito da escolha da estratégia genérica de competição e dos sistemas de controle gerencial (SCG) no desempenho organizacional de 73 empresas de médio e grande porte localizadas no Espírito Santo, tendo a teoria da contingência 
como plataforma teórica de apoio. Na parte que relaciona o uso de instrumentos gerenciais para avaliação do desempenho, concluíram que as empresas que optam pela estratégia de diferenciação adotam práticas mais contemporâneas de controle gerencial, enquanto naquelas optantes pela estratégia de custos baixos verifica-se o predomínio de práticas tradicionais. Aduzem, também, que esse resultado indica que as empresas que escolhem o posicionamento de diferenciação demandam ferramentas gerenciais com escopos mais amplos e focados no planejamento, o que se coaduna com Van der Stede (2000) e Chenhall (2003).

Para explicar esse resultado, Junqueira et al. (2016) aventam a possibilidade de que as características das estratégias de diferenciação requerem uma estrutura de controles administrativos mais flexível, o que obriga as empresas que atuam com base nesse posicionamento estratégico a utilizar principalmente ferramentas mais modernas. Por outro lado, quando consideradas as adotantes do posicionamento de custos baixos, tal pesquisa evidenciou que o SCG tem outra configuração, sendo composto majoritariamente por ferramentas tradicionais, que focam mais o controle operacional. Portanto, tais autores defendem que as escolhas estratégicas das empresas da amostra podem ser consideradas como um dos fatores contingenciais influenciadores do desenho do SCG.

A influência do posicionamento estratégico constatada por Junqueira et al. (2016) contradiz o resultado do teste de Mann-Whitney aplicado para o contexto das 88 pequenas fábricas desta pesquisa. Nessa direção, entre as 26 práticas gerenciais citadas, somente nos casos do "planejamento tributário" (estágio 2) e dos "indicadores-chave de performance (KPIs)" (estágio 4) é que se verificou indicativo estatístico no sentido de haver diferença nos níveis de uso entre os dois grupos de pequenas empresas fabris segregados quanto ao tipo de posicionamento estratégico. Nas outras 24 práticas restou evidente que não haveria influência do posicionamento estratégico escolhido no nível de utilização, levando à aceitação da hipótese nula.

Convém ressaltar os contextos díspares dessas duas pesquisas, pois a primeira levou em conta 73 empresas capixabas de médio e grande porte, enquanto o estudo ora relatado está circunscrito às 88 pequenas fábricas de uma das microrregiões do sul de Santa Catarina. A disparidade de porte dos dois conjuntos de empresas utilizadas nessas duas investigações provavelmente é o fator que mais pesa nessa distinção, especialmente porque as grandes companhias têm mais recursos (humanos e financeiros) para adotar práticas gerenciais mais sofisticadas.

\section{CONSIDERAÇÕES FINAIS}

O objetivo deste estudo foi identificar a influência do posicionamento estratégico na adoção de ferramentas gerenciais financeiras no contexto de pequenas indústrias da microrregião da Amurel e, adicionalmente, encontrar resposta para hipótese acerca da possibilidade de que o nível de utilização das práticas de gestão financeira seja igual nas empresas de pequeno porte, independentemente do posicionamento estratégico adotado.

Nessa direção, os autores consideram que tal finalidade foi atingida porque a tabulação das respostas permitiu conhecer as práticas gerenciais mais utilizadas, bem como obter indicativo estatístico no sentido de aceitar a hipótese de que não haveria influência do posicionamento estratégico escolhido no nível de utilização dessas práticas.

Quanto aos resultados mais relevantes, além das características das empresas em lume, cabe salientar os seguintes aspectos:

a) As práticas gerenciais do primeiro e do segundo estágio são as mais utilizadas (com média $55,91 \%$ e $69,32 \%$, respectivamente), se comparadas com os instrumentos integrantes do terceiro $(40 \%)$ e do quarto estágio $(44,46 \%)$. Esse resultado se coaduna com pesquisas 
anteriores que atestam um índice maior de uso das práticas consideradas tradicionais, em detrimento daquelas mais recentes.

b) A hipótese de pesquisa que cogitava não haver interferência do posicionamento estratégico no patamar de utilização das práticas gerenciais pesquisadas foi aceita. Nesse rumo, os dois grupos amostrais (segmentados quanto à adoção das estratégias genéricas "diferenciação" e "custos baixos") mostraram médias assemelhadas, do ponto de vista estatístico pelo teste de Mann-Whitney, em 24 das 26 práticas consideradas. Tal resultado contraria em parte a pesquisa de Junqueira et al. (2016), que apurou haver influência da estratégia adotada no nível de utilização de determinadas métricas de avaliação de desempenho.

No que tange às contribuições da pesquisa, é pertinente ressaltar a possibilidade de conhecer o contexto das pequenas empresas fabris de uma microrregião do sul de Santa Catarina em termos das práticas gerenciais priorizadas e, adicionalmente, apontar evidência estatística de que o posicionamento estratégico escolhido por essas indústrias de pequeno porte não afeta o nível de utilização das práticas financeiras citadas nesse contexto empresarial.

Em relação às limitações da pesquisa, convém mencionar dois aspectos. O primeiro refere-se à peculiaridade de ser utilizado um questionário padronizado, cujas questões podem levar a interpretações equivocadas dos respondentes. Ou seja, não foram checadas/trianguladas as respostas obtidas nos controles internos das firmas abrangidas, assumindo-se que as respostas coligidas expressam o contexto administrativo dessas empresas. $\mathrm{O}$ segundo aspecto diz respeito ao tamanho da amostra utilizada, pois as 88 pequenas indústrias estudadas foram aquelas cujos respondentes aceitaram participar. Destarte, a priori, se deve assumir que os resultados oriundos não podem ser extrapolados para outros contextos empresariais ou regionais.

Como recomendações para estudos futuros, seria interessante expandir o número de empresas envolvidas e aplicar investigação assemelhada abrangendo pequenas empresas de outras regiões do país (ou de outros países) a fim de permitir o cotejamento dos resultados em bases mais homogêneas.

\section{REFERÊNCIAS}

Abdel Al, S. F., \& McLellan, J. D. (2013). Strategy and management accounting practices alignment and its effects on organizational performance. Journal of Accounting Business and Management, 20(1), 1-27.

Abdel-Kader, M., \& Luther, R. (2006). Management accounting practices in the British food and drinks industry. British Food Journal, 108(5), 36-357.

Abdel-Kader, M., \& Luther, R. (2008). The impact of firm characteristics on management accounting practices: a UK-based empirical analysis. The British Accounting Review, 40(1), 2-27.

Ahmad, K. (2014). The adoption of management accounting practices in Malaysian small and medium size enterprises. Asian Social Science, 7(2), 236-249.

Almeida, K. K. N., \& Callado, A. A. C. (2018). Relação entre o poder do cliente e práticas de contabilidade gerencial. Revista Gestão Organizacional-RGO, 11(2), 61-78.

Almeida, F. M. de, Valadares, J. L., \& Sediyama, G. A. (2017). A contribuição do empreendedorismo para o crescimento econômico dos estados brasileiros. Revista de Empreendedorismo e Gestão de 
Pequenas Empresas, 6(3), 466-494.

Andrade, M. M. de. (2002). Como preparar trabalhos para cursos de pós-graduação: noções práticas (5a ed.). São Paulo: Atlas.

Beuren, I. M., \& Fiorentin, M. (2014). Influência de fatores contingenciais nos atributos do sistema de contabilidade gerencial: um estudo em empresas têxteis do Estado do Rio Grande do Sul. Revista de Ciências da Administração, 16(38), 196-212.

Bruni, A. L. (2012). SPSS: guia prático para pesquisadores. São Paulo: Atlas.

Callado, A. A. C. (2016). Relações entre o número de indicadores de desempenho utilizados e fatores contingenciais: evidências do contexto de uma cadeia agroalimentar de suprimentos. Revista Contabilidade Vista \& Revista, 27(2), 48-63.

Castro, J. A. F. (2015). Contingency factors that influence the design of organizational structure. Journal of Business, 2(2), 38-56.

Chenhall, R. H., \& Langfield-Smith, K. (1998). Adoption and benefits of management accounting practices: an Australian study. Management Accounting Research, 9(1), 1-19.

Chenhall, R. H., \& Chapman, C. S. (2006). Theorising and testing fit in contingency research on management control systems. In Z. Hoque (ed.). Methodological issues in accounting research: theories, methods and issues (pp. 35-52). London: Spiramus Press.

Chenhall, R. H. (2003). Management control systems design within its organizational context: findings from contingency-based research and directions for the future. Accounting, Organizations and Society, 28(2-3), 127-168.

Chenhall, R. H. (2006). Theorizing contingencies in management control systems research. In C. S. Chapman, A. G. Hopwood, \& M. D. Shields (org.). Handbooks of Management Accounting Research, 1 (pp. 263-205), London: Elsevier.

Dalchiavon, A., Wernke, R., \& Zanin, A. (2017). Práticas de controladoria utilizadas em cooperativa central de crédito: estudo de caso. Revista de Gestão e Organizações Cooperativas - RGC, 4(8), $13-32$.

Dalmoro, M., \& Vieira, K. M. (2013). Dilemas na construção de escalas tipo Likert: o número de itens e a disposição influenciam nos resultados? Revista Gestão Organizacional-RGO, 6(ed. especial), 161-174.

Donaldson, L. (2012). Teoria da contingência estrutural. In S. R. Clegg, C. Hardy, \& W. R. Nord, Handbook de estudos organizacionais. São Paulo: Atlas.

Donaldson, L. (2001). The contingency theory of organizations. London: Sage.

Gil, A. C. (2010). Métodos e técnicas de pesquisa social. São Paulo: Atlas. 
Honorio, F. M. M., \& Bonemberger, S. Z. (2019). Aplicação de ferramentas de apoio gerencial contábil em uma microempresa de confecções. Revista de Empreendedorismo e Gestão de Pequenas Empresas, 8(1), 201-218.

International Federation of Accountants. (1998). International Management Accounting Practice Statement: Management Accounting Concepts. New York.

Jordão, R. V. D., \& Souza, A. A. (2013). Aquisição de empresas como fator de mudança no sistema de controle gerencial: uma análise estratégica sob a perspectiva da Teoria Contingencial. Revista Universo Contábil, 9(3), 75-103.

Joshi, P. L. (2001). The international diffusion of new management accounting practices: the case of India. Journal of International Accounting, Auditing \& Taxation, 10(1), 85-109.

Junqueira, E., Dutra E. V., Zanquetto Filho, H., \& Gonzaga, R. P. (2016). Efeito das escolhas estratégicas e dos sistemas de controle gerencial no desempenho organizacional. Revista Contabilidade \& Finanças, 27(72), 334-348.

Klein, L., \& Almeida, L. B. de. (2017). A influência dos fatores contingenciais na adoção de práticas de contabilidade gerencial nas indústrias paranaenses. Revista Universo Contábil, 13(3), 90-119.

Lavarda, C. E. F., \& Gorla, M. C. (2012). Estudo bibliométrico sobre a teoria contingencial aplicada à pesquisa orçamentária. Anais do Congresso USP de Controladoria e Contabilidade, São Paulo, SP, Brasil, 12.

Leite, E. G. (2013). Adoção de práticas de controladoria por empresas atuantes no Brasil: um estudo sob a ótica da teoria da contingência. Dissertação Mestrado em Controladoria e Finanças, Universidade do Vale do Rio dos Sinos, São Leopoldo, RS, Brasil.

Leite, E. G., Diehl, C. A., \& Manvailer, R. H. M. (2015). Práticas de controladoria, desempenho e fatores contingenciais: um estudo em empresas atuantes no Brasil. Revista Universo Contábil, 11(2), 85-107.

Maletic, D., Maletic, M., Al-Najjar, B., Gotzamani, K., Gianni, M., Kalinowski, T., Gomiscek, B. (2017). Contingency factors influencing implementation of physical asset management practices. Organizacija, 50(1), 3-16.

Malik, K., \& Jasinska-Biliczak, A. (2018). Innovations and other processes as identifiers of contemporary trends in the sustainable development of SMEs: the case of emerging regional economies. Sustainability, 10(5), 1361.

Mclellan, J. D. (2014). Management accounting theory and practice: measuring the gap in United States Business. Journal of Accounting, Business \& Management, 21(1), 53-68.

Mintzberg, H., Ahlstrand, B., \& Lampel, J. (2010). Safári de estratégia: um roteiro pela selva do planejamento estratégico (2a ed.). Porto Alegre: Bookman.

Moterle, S., Wernke, R., \& Junges, I. (2019). Conhecimento sobre gestão financeira dos dirigentes de 
pequenas empresas do sul de Santa Catarina. Revista de Administração, Contabilidade e Economia $-R A C E, 18(1), 1-26$.

Nigri, G., \& Baldo, M. (2018). Sustainability reporting and performance measurement systems: how do small-and medium-sized benefit corporations manage integration? Sustainability, 10(12), 1-17.

Oro, I. M., \& Lavarda, C. E. F. (2019). Interface dos sistemas de controle gerencial com a estratégia e medidas de desempenho em empresa familiar. Revista Contabilidade e Finanças, 30(79), 14-27.

Otley, D. (2016). The contingency theory of management accounting and control: 1980-2014. Management Accounting Research, 31(june), 45-62.

Panosso, A., Camanho, R. R., Espejo, M. M. dos S. B., \& Abbas, K. (2017). Influência das ferramentas de controle gerencial no desempenho: estudo empírico em empresas industriais paranaenses. Enfoque: Reflexão Contábil, 36(2), 1-17.

Pavlatos, O., \& Paggios, I. (2009). Management accounting practices in the Greek hospitality industry. Managerial Auditing Journal, 24(1), 81-98.

Porter, M. (1991). Estratégia competitiva: técnicas para análise de indústrias e da concorrência (8a ed.). Rio de Janeiro: Campus.

Rauen, F. (2015). Roteiros de iniciação científica: os primeiros passos da pesquisa científica desde a concepção até a produção e a apresentação. Palhoça: Editora Unisul.

Richardson, R. J. (1999). Pesquisa social: métodos e técnicas. São Paulo: Atlas.

Rufatto, I. (2018). Niveis de utilização e de importância das práticas de controladoria adotadas por cooperativas agrícolas paranaenses. 2018. Dissertação Mestrado em Ciências Contábeis e Administração, Universidade Comunitária da Região de Chapecó, Chapecó, SC, Brasil.

Santos, V., Dorow, D. R., \& Beuren, I. M. (2016). Práticas gerenciais de micro e pequenas empresas. Revista Ambiente Contábil, 8(1), 153-186.

Santos, V., Corrêa, N. L., Beuren, I. M., \& Gomes, T. (2019). Relação entre ciclo de vida organizacional e uso de instrumentos de contabilidade gerencial. Enfoque: Reflexão Contábil, $39(2), 67-85$.

Scapens, R. W. (2006). Understanding management accounting practices: a personal journey. The British Accounting Review, 38(1), 1-30.

Siska, L. (2016). The contingency factors affecting management accounting in czech companies. Acta Universitatis Agriculturae et Silviculturae Mendelianae Brunensis, 64(4), 1383-1392.

Sulaiman, M., Ahmad, N. N. N., \& Alwi, N. (2004). Management accounting practices in selected Asian countries: a review of the literature. Managerial Auditing Journal, 19(4), 493-508.

Triola, M. F. (2005). Introdução à estatística (9a ed.). Rio de Janeiro: LTC. 
Van Der Stede, W. A. (2000). The relationship between two consequences of budgetary controls: budgetary slack creation and managerial short-term orientation. Accounting, Organizations and Society, 25(6), 609-622.

Valeriano, C. E. B. (2012). Ciclo de vida organizacional e artefatos de contabilidade gerencial: uma investigação nas 250 pequenas e médias empresas que mais cresceram no Brasil entre $2008 e$ 2010. Dissertação Mestrado em Contabilidade, Universidade de São Paulo, São Paulo, SP, Brasil. 